\title{
Questions linger over stress-induced stem cells
}

Investigation confirms STAP cells were contaminated, but mystery still surrounds original results.

Heidi Ledford

31 December 2014

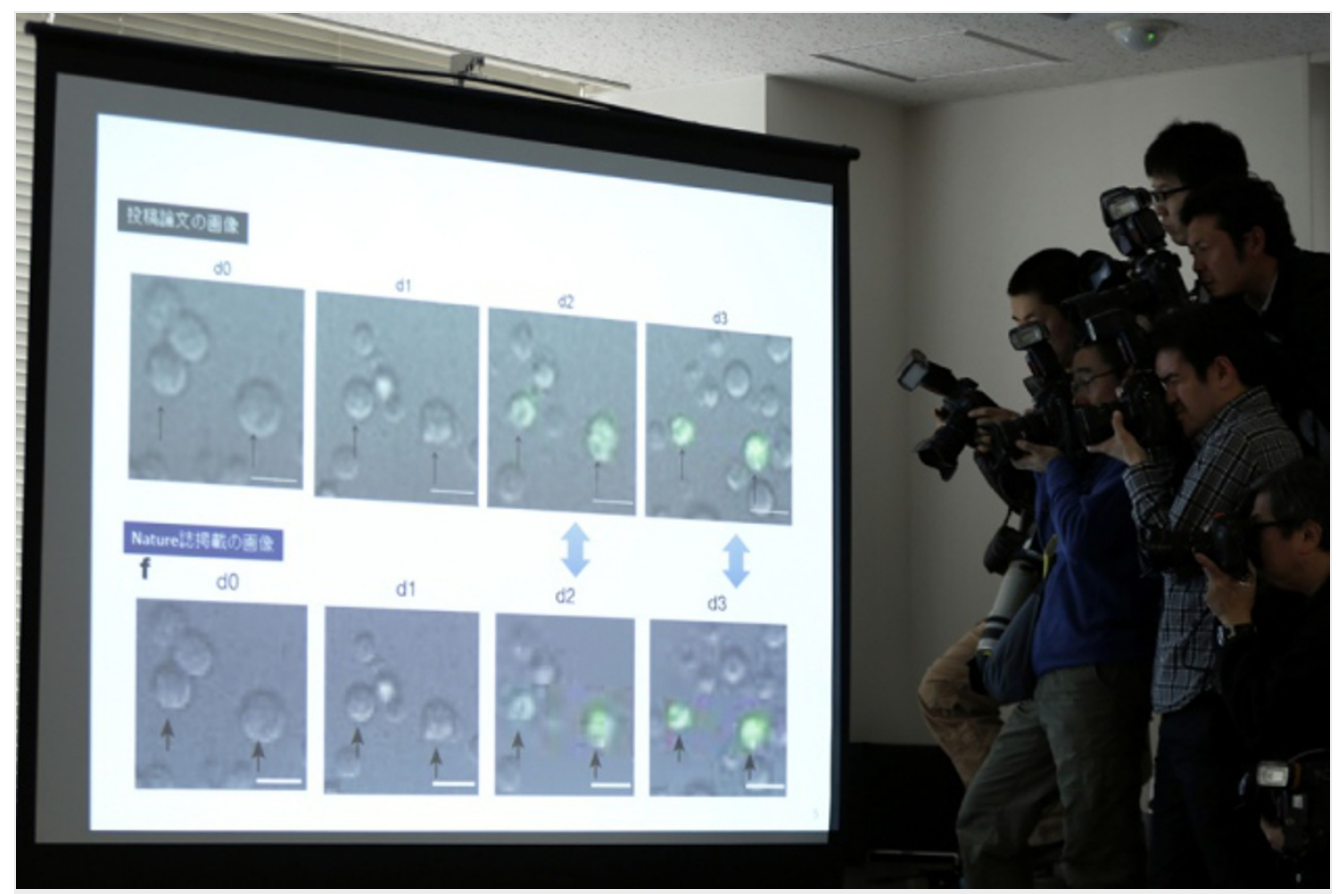

Kiyoshi Ota/Bloomberg via Getty

Problems with stem-cell papers noted at a RIKEN conference in March 2014 have now been further analysed.

The latest investigation into a debunked method of generating stem cells has left researchers grappling with questions about what went wrong in a laboratory at the RIKEN research institute in Japan.

The final report from the independent investigation, released on 26 December, bolstered suspicions that the stem cells — which were supposedly generated by applying stress to ordinary adult cells in an acid bath - were actually embryonic stem cells that had been introduced to the samples. But investigators were unable to determine how the contamination occurred or whether it was accidental.

The investigation also has not explained one of the most notable features of the cells — their ability to form a placenta — something that embryonic stem cells do not generally do. "That is still one question that to me is still a mystery," says Manuel Serrano, a cancer biologist who has worked with stem cells at the Spanish National Cancer Research Centre in Madrid. 
Serrano, like many of his colleagues, was intrigued by the papers, published in Nature in January 2014, reporting that adult cells could behave like stem cells after experiencing severe stress 1,2 . To him, the premise made sense - there was ample evidence in the literature that stressed cells were prone to taking on new identities. "Cells respond to damage by trying to acquire the plasticity to repair the tissue," he says. "But it was surprising that this stress was sufficient to fully reprogram the cell."

Serrano tasked two researchers in his lab with making stem cells using the authors' method - called stimulus-triggered acquisition of pluripotency (STAP). He initially urged them to keep trying when their attempts failed. But within about two months, Serrano advised them to abandon their efforts. Reports were pouring in from other labs that could not reproduce the method, and questions arose about the validity of data in the papers.

In response to the controversy, RIKEN launched two investigations into the work, much of which was carried out at the RIKEN Center for Developmental Biology in Kobe. An internal review reported in March that lead investigator Haruko Obokata had manipulated images in the two Nature publications. The papers were retracted in July $^{3}$.

The second investigation, carried out by a team of scientists not employed by RIKEN, delved deeper, analysing cell lines and tissue samples from the laboratories to determine their provenance. In addition to unearthing two more fabrications in figures from the January publications, the team found that three 'STAP cell lines contained embryonic stem cells.

The results confirmed suspicions in the field, says George Daley, a stem-cell researcher at Children's Hospital Boston in Massachusetts. "The fact that the reported STAP cells had different properties from embryonic stem cells was what piqued many people's interest," he says. "But there was always the concern that some part of the data could have come from the use of standard embryonic stem-cell lines."

Despite poring over lab notebooks and records, the investigators commissioned by RIKEN said that they could not ascertain how the contamination occurred. They noted, however, that it was difficult to imagine an accidental contamination with three distinct embryonic stemcell lines. Five stem-cell researchers contacted by Nature agreed with this assessment.

However it occurred, contamination explains the cells' ability to differentiate into a variety of types. But it does not explain how the cells could be coaxed to form placental tissue. "Generally speaking, we think that embryonic stem cells have lost the capacity to make those placental cell types," says Janet Rossant, a stem-cell researcher at the Hospital for Sick Children in Toronto, Canada.

Some researchers have suggested that the authors altered the images or concluded incorrectly that naturally occurring fluorescence which can be seen in placenta and other blood-rich tissues - was generated by the fluorescent marker carried by the stem cells. Daley believes such a mistake is unlikely, given the expertise of the authors on the paper.

Another possibility is that the STAP cell cultures were contaminated not only with embryonic stem cells, but also with trophoblasts, a type of cell that can form the placenta. Trophoblasts have a different shape and express different genes from embryonic stem cells, but the genetic analysis done during the RIKEN investigation might not have distinguished them, particularly if they were present in low numbers.

Rossant says that researchers have reported that some embryonic stem cells, under the right conditions, can give rise to placental cells ${ }^{4}$. "It could be that they did have conditions that drove the cells toward more trophoblasts, which would be interesting in itself," she says.

But although Rossant is eager for the field to learn more about how to make stem cells more plastic, she is not keen for researchers to sift for those data in the wreckage of the STAP story. "It is definitely time for everyone to move on from STAP cells," she says.

Nature I doi:10.1038/nature.2014.16648

\section{- References}

1. Obokata, H. et al. Nature 505, 641-647 (2014).

2. Obokata, H. et al. Nature 505, 676-680 (2014).

3. Obokata, H. et al. Nature 511, 112 (2014). 
4. Morgani, S. M. \& Brickman, J. M. Phil. Trans. R. Soc. Lond. B 369, 20130549 (2014).

Nature ISSN0028-0836 ESSN 1476-4687

\section{SPRINGER NATURE}

(c) 2019 Macmillan Publishers Limited, part of Springer Nature. All Rights Reserved. partner of AGORA, HINAR, OARE, INASP, CrossRef and COUNIER 